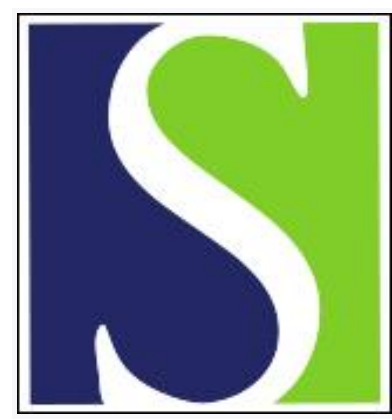

Scand J Work Environ Health 2009;35(5):397-399

https://doi.org/10.5271/sjweh.1341

Published online: 25 Jun 2009, Issue date: 00 Oct 2009

Suggested excess of occupational cancers in Norwegian offshore workers: preliminary results from the Cancer Registry Offshore Cohort

by Aas GB, Aagnes B, Strand LA, Grimsrud TK

Affiliation: Cancer Registry of Norway, Oslo, Norway

Key terms: cancer; cancer of the pleura; Cancer Registry Offshore Cohort; leukemia; Norway; occupational cancer; offshore worker; prospective cohort study; short communication; upstream petroleum industry

This article in PubMed: www.ncbi.nlm.nih.gov/pubmed/19554245 


\title{
Suggested excess of occupational cancers in Norwegian offshore workers: preliminary results from the Cancer Registry Offshore Cohort
}

\author{
by Gjøril Bergva Aas, MSoc, ${ }^{1}$ Bjarte Aagnes, Cand mag, ${ }^{1}$ Leif Åge Strand, MSc, ${ }^{1}$ Tom K Grimsrud, MD ${ }^{1}$
}

\begin{abstract}
Aas GB, Aagnes B, Strand LÅ, Grimsrud TK. Suggested excess of occupational cancers in Norwegian offshore workers: preliminary results from the Cancer Registry Offshore Cohort. Scand J Work Environ Health. 2009;35(5):397-399.
\end{abstract}

Objective The aim of this communication was to report the overall incidence of cancer in a cohort of male Norwegian offshore oil workers.

Methods The Offshore Cohort was comprised of $>25000$ men who were employed at installations in the North Sea in the period 1965-1999, and who responded to a questionnaire that included work history offshore, other occupational experience, education, leisure-time activities, and lifestyle factors. Calculating standardized incidence ratios (SIR), we compared the number of prospective incident cancers diagnosed between 1999 and 2005 with those expected for age-, gender- and period-specific rates in the general Norwegian population.

Results The overall cancer incidence did not differ from that of the reference population [SIR=1.0, 95\% confidence interval $(95 \% \mathrm{CI}) 1.0-1.1, \mathrm{~N}=695]$. There were indications of excess risks of acute myeloid leukemia $(\mathrm{SIR}=2.0,95 \% \mathrm{CI} 1.0-3.7)$ and cancer of the pleura ( $\mathrm{SIR}=2.2,95 \% \mathrm{CI} 0.9-4.6)$. No data on occupational history was used in these preliminary analyses.

Conclusions The cohort was relatively young and an extended observation period would be important for in-depth analyses. The suggested excess of leukemia and cancer of the pleura may be linked to occupational exposure during employment offshore; this issue needs to be addressed in further studies.

Key terms cancer of the pleura; leukemia; prospective cohort study; short communication; upstream petroleum industry.

Exploration of oil and gas on the Norwegian continental shelf began in the mid 1960s. Production started in 1971 and the activity expanded rapidly throughout the 1970s and 1980s. With 52 oil fields currently in production, Norway is, by volume, the world's fifth largest oil exporter and tenth largest oil producer (1).

Many occupational factors in the offshore work environment are known to cause disease. Among these are physical, psychosocial, and chemical hazards, recently reviewed by Gardner (2). Chemical hazards involve exposure to toxic, corrosive, irritant, and sensitizing substances, as well as known or suspected carcinogens (2). Some exposure situations are specific to work on offshore installations, although many components are also present in onshore oil activity.

Epidemiological studies have identified associations between exposures in oil-related industries and various cancer forms, such as mesothelioma, hematopoietic cancers, malignant melanoma, cancer of the lung, and cancer of the prostate (3-7). Based on this, our attention was primarily directed towards cancer of the lung, pleura, prostate, melanoma of the skin, leukemia, and multiple myeloma.

It has been widely recognized that benzene causes acute myeloid leukemia (7). Furthermore, the association between the inhalation of asbestos fibers and cancer of the pleura has been well documented. Both lung cancer and cancer of the bladder can be caused by combustion products present in the work atmosphere, even if the most common cause is smoking (3-5). Additionally, leisure time on the platform may differ from life on the mainland with its 24-hour abundance of warm dishes, regulation of alcohol consumption, and low tobacco retail prices $(8)$.

\footnotetext{
1 Cancer Registry of Norway, Oslo, Norway.
}

Correspondence to: Gjøril Bergva Aas, Cancer Registry of Norway, Montebello NO-0310 Oslo, Norway. [E-mail: gjoril.bergva.aas@ kreftregisteret.no] 


\section{Methods}

In 1989, together with employee and management representatives, the Cancer Registry of Norway launched a collaborative effort to assess the cancer risk among offshore workers. In addition to the fact that no complete list of Norwegian workers and their platform experience was available, the project had a late start in 1996. Names and identities of workers potentially engaged in platform work in the present or past were collected from several sources such as employers, labor unions, and maritime schools offering safety and oil technology courses. Such courses were not restricted to offshore workers. The list was created with a high probability of including all offshore workers at the cost of including an unknown but possibly large proportion of mariners and oil workers who were never employed in platform work.

In 1998 and early 1999, a self-administered questionnaire was distributed by mail to the home addresses of more than 57000 possible offshore workers known to be alive and residents in Norway. For inclusion in the study, the workers had to have worked at installations in the North Sea for a minimum of 20 days within a period of four months between 1965 and 1999. Some 35000 answers were received, of which slightly more than 7000 respondents declared never to have worked offshore. The remaining 28000 respondents constituted the Cancer Registry Offshore Cohort - 9\% of which were women - and provided data on education, work history offshore and elsewhere, leisure-time activities, and lifestyle factors, such as smoking habits, alcohol consumption, physical activity, and diet (8).

This short communication is based on the linkage between the Offshore Cohort and the Cancer Registry national database of incident cancers, and a report prepared for the Norwegian Ministry of Labor and Social Inclusion (Arbeids- og inkluderingsdepartementet) in December 2007 (9).

Less than 70 individuals ( $2.3 \%$ of the cohort) were excluded due to death or emigration before the start of the follow-up; less than ten $(0.3 \%)$ failed to be identified, probably as a result of a change in their unique personal identification number. A total of 25348 men remained for linkage to the national Cancer Registry database. Each worker was followed from 1 July 1999 until the date of death, emigration, or 31 December 2005 (whichever came first). Reporting of new cases of cancer is compulsory in Norway, and data from a number of sources ensured a high degree of completeness (10). Standardized incidence ratios (SIR) were calculated from five-year age-, period-, and gender-specific rates for the entire Norwegian population (4.6 million by 1 January 2006). A standard grouping of diagnoses, based on a modified version of the International Clas-

sification of Diseases (ICD-7), was used for all cancers, except for acute myeloid leukemia, which was classified according to International Classification of Diseases for Oncology (ICDO-3).

No data on occupation, exposures, or lifestyle was used for these analyses, the aim of which was to address the total number of cases and shed some light on certain forms of cancer that may be of special relevance for offshore workers.

\section{Results}

The total number of cancers was close to the expected one (table 1). The data suggested a slightly increased risk of cancers of the lung and prostate, and leukemia and multiple myeloma combined. A doubling of the risk was suggested for cancer of the pleura, based on seven cases only. Among the leukemias, there were ten cases of acute myeloid leukemia versus five that were expected based on the background rates.

\section{Discussion}

The results suggested an increased risk of cancer of the pleura and acute myeloid leukemia. Such a risk in a cohort predominated by petroleum workers may very well be of an occupational origin, although our general focus and the preliminary character of the data do not allow for firm conclusions. The findings are based on few cases. Interestingly, an excess risk

Table 1. Observed and expected numbers of selected cancers 1999-2005 among male members of the Cancer Registry Offshore Cohort. $(\mathrm{SIR}=$ standardized incidence ratio; $95 \% \mathrm{Cl}=$ $95 \%$ confidence interval; ICD-0 = International Classification of Diseases for Oncology)

\begin{tabular}{lrrrr}
\hline Cancer site $^{\text {a }}$ & Observed & Expected & SIR & $95 \% \mathrm{Cl}$ \\
\hline Lung (162) & 87 & 74.2 & 1.2 & $0.9-1.5$ \\
Pleura (163) & 7 & 3.2 & 2.2 & $0.9-4.6$ \\
$\begin{array}{l}\text { Prostate (177) } \\
\text { Melanoma of skin (190) }\end{array}$ & 163 & 146.9 & 1.1 & $1.0-1.3$ \\
$\begin{array}{l}\text { Leukemia \& } \\
\text { multiple myeloma (207) }\end{array}$ & 36 & 42.7 & 1.0 & $0.8-1.4$ \\
$\quad \begin{array}{l}\text { Acute myeloid } \\
\text { leukemia } \\
\quad \text { ICDO-3-based) }\end{array}$ & 10 & 5.0 & 1.2 & $0.9-1.7$ \\
$\begin{array}{l}\text { Total number of } \\
\text { cancers (all sites) } \\
\text { (140-207) }\end{array}$ & 695 & 667.1 & 1.0 & $1.0-3.7$ \\
$\begin{array}{l}\text { a Code of the International Classification of Diseases, seventh revision, in } \\
\text { parentheses. }\end{array}$ & & & &
\end{tabular}


of lymphohematopoietic neoplasms, involving acute myeloid leukemia and multiple myeloma, has recently been found in a registry-based study of Norwegian offshore oil workers at the University of Bergen (6). The degree of cohort overlap between the two studies is not known in detail, but six out of the ten cases of acute myeloid leukemia in our study were diagnosed after the end of follow-up for the registry-based study from Bergen (6). An association with benzene exposure should be considered for the leukemias, although exposure might have occurred in work outside the offshore activity, such as on oil tankers or during land-based activities. The number of pleural cancers suggests an element of former asbestos exposure above the population level.

The increased incidence of prostate cancer may be the result of regular health surveillances required for offshore health certificates. A selection based on health examinations would even be expected to introduce a healthy worker effect, which was not found in the total number of cancer cases.

The crude response rate of $61 \%$ indicates that it would be of interest to study further the representativeness of the findings, although a substantial proportion of the people appearing on the original lists were not expected to be employed in offshore work.

Additional follow-up time and more detailed information on occupational history and exposures may allow for more in-depth analyses of the cancer pattern of this large cohort.

\section{Acknowledgements}

The report, on which this communication is based, was funded by the Norwegian Ministry of Labor and Social Inclusion (Arbeids- og inkluderingsdepartementet). No conflict of interest exists.

\section{References}

1. Facts - the Norwegian petroleum sector 2007 [report]. Oslo, Stavanger: Norwegian Petroleum Directorate; 2007.

2. Gardner R. Overview and characteristics of some occupational exposures and health risks on offshore oil and gas installations. Ann Occup Hyg. 2003;47:201-10.

3. Gun RT, Pratt N, Ryan P, Roder D. Update of mortality and cancer incidence in the Australian petroleum industry cohort. Occup Environ Med. 2006;63:476-8.

4. Schnatter AR, Thériault G, Katz AM, Thompson FS, Donaleski D, Murray N. A retrospective mortality study within operating segments of a petroleum company. Am J Ind Med. 1992;22:209-29.

5. Lewis RJ, Schnatter AR, Drummond I, Murray N, Thompson FS, Katz AM, et al. Mortality and cancer morbidity in a cohort of Canadian petroleum workers. Occup Environ Med. 2003;60:918-28.

6. Kirkeleit J, Riise T, Bråtveit N, Moen BE. Increased risk of acute myelogenous leukemia and multiple myeloma in a historical cohort of upstream petroleum workers exposed to crude oil. Cancer Causes Control. 2008;19:13-23.

7. Schnatter AR, Rosamilia K, Wojcik NC. Review of the literature on benzene exposure and leukemia subtypes. Chem Biol Interact. 2005;153-4:9-21.

8. Strand LA, Andersen A. Innsamling av bakgrunnsdata og etablering av kohort [Establishing of cohort and collection of data][report]. Oslo: Cancer Registry of Norway; 2001.

9. Aas GB, Strand LÅ, Grimsrud TK. Foreløpig vurdering av kreftforekomst og skisse for videre studier [Preliminary results and framework for further studies][report]. Oslo: Cancer Registry of Norway; 2007.

10. Larsen IK, Småstuen M, Johannesen TB, Langmark F, Parkin DM, Bray F, Møller B. Data quality at the Cancer Registry of Norway: an overview of comparability, completeness, validity and timeliness. Eur J Cancer. 2009;45(7):1218-31.

Received for publication: 10 March 2009 